\title{
The effect of a bleaching agent on the pigment removal and the bond strength of bulk-fill resin composites: an in vitro study
}

\author{
Efeito dos agentes clareadores na remoção de pigmentos e na resistência de união de resinas \\ compostas bulk-fill: um estudo in vitro
}

\author{
Caroline de Farias CHARAMBA ${ }^{a}$, Renally Bezerra Wanderley LIMA ${ }^{b *}$, Sônia Saeger MEIRELES ${ }^{a}$, \\ Rosângela Marques DUARTE ${ }^{a}$, Ana Karina Maciel ANDRADE ${ }^{a}$ \\ ${ }^{a}$ UFPB - Universidade Federal da Paraíba, João Pessoa, PB, Brasil

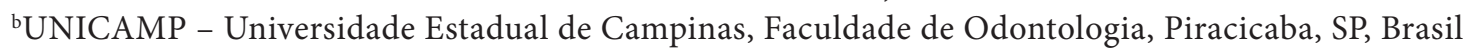

\begin{abstract}
Resumo
Introdução: Em busca de simplificar a técnica, reduzir o tempo requerido para as restaurações adesivas, resinas compostas bulk-fill (RCBF) estão sendo desenvolvidas para serem aplicadas em incrementos com espessura de até $4 \mathrm{~mm}$. Objetivo: Avaliar a alteração de cor $(\triangle \mathrm{E})$ e resistência de união $(\mu \mathrm{TBS})$ de RCBF a dentina após imersão em bebidas e aplicação de um sistema clareador. Método: Foram utilizados 45 dentes molares humanos que foram distribuídos aleatoriamente em três grupos de acordo com o material restaurador $(\mathrm{n}=15)$ : Filtek Bulk Fill, Tetric $\mathrm{N}$ Ceram Bulk Fill e Filtek Z100. Os dentes restaurados foram imersos em café, vinho e água destilada $(n=5)$ durante 72 horas. Os parâmetros de cor foram mensurados utilizando um espectrofotômetro, tendo como base o CIE L*a* $\mathrm{a}^{*}$, antes e após o manchamento e aplicação dos agentes clareadores. Consequentemente, os dentes foram seccionados para a obtenção de espécimes para o teste de microtração. Os valores de $\Delta \mathrm{E}$ foram analisados aplicando os testes de Kruskal-Wallis e Wilcoxon e os valores de $\mu$ TBS foram analisados aplicando ANOVA e o teste de Bonferroni $(\mathrm{p}<0,05)$. Resultado: Não houve diferença significante nos valores de $\triangle \mathrm{E}$ quando as RCBFs foram comparadas a resina composta convencional (RCC) na maioria dos grupos experimentais. Os valores de $\Delta \mathrm{E}$ não apresentaram diferença estatística antes e após a aplicação do agente clareador para todas as resinas testadas. As RCBFs demonstraram maiores valores de $\mu$ TBS comparado a RCC após exposição a água destilada, vinho e agente clareador. Conclusão: As RCBFs demonstraram uma similar estabilidade de cor quando comparado a RCC. As RCBFs apresentaram maior resistência de união a dentina que a RCC na maioria das condições avaliadas. O agente clareador não foi efetivo no clareamento dos dentes restaurados.
\end{abstract}

Descritores: Resinas compostas; clareamento dental; resistência a tração.

\begin{abstract}
Introduction: In order to simplify the technique, reduce the time required for direct adhesive restorations, bulk-fill resin composites have been developed be applied in bulk placement up to $4 \mathrm{~mm}$ increments. Objective: Evaluating the color change $(\triangle \mathrm{E})$ and the microtensile bond strength ( $\mu \mathrm{TBS}$ ) of bulk fill resin composites (BFRC) to dentin after the immersion in regular beverages and the application of bleaching systems. Method: Forty-five human molar teeth were randomly distributed in three groups according to the filling material $(\mathrm{n}=15)$ : Filtek Bulk Fill, Tetric $\mathrm{N}$ Ceram Bulk Fill and Filtek Z100. The restored teeth were immersed in coffee, wine and distilled water $(n=5)$ for 72 hours. The color parameters were measured using a spectrophotometer, having as basis the CIE $\mathrm{L}^{\star} \mathrm{a}^{\star} \mathrm{b}^{\star}$, before and after tooth staining and application of bleaching processes. Subsequently, the teeth were sectioned to obtain the specimens for the microtensile testing. The $\Delta \mathrm{E}$ values were analyzed applying the Kruskal-Wallis and the Wilcoxon tests, and the $\mu$ TBS values were analyzed applying the ANOVA and the Bonferroni tests $(\mathrm{p}<0.05)$. Result: There were no significant differences in the $\triangle \mathrm{E}$ values when comparing the BFRCs to the conventional resin composite (CRC) in most of the experimental groups. The $\Delta \mathrm{E}$ values did not present significant differences before and after the application of bleaching processes for all the tested resin composites. The BFRCs presented higher $\mu$ TBS values than the CRC after exposure to distilled water, wine and bleaching agent. Conclusion: The studied BFRCs presented similar color stability to the CRC. The BFRCs presented higher bond strength to the dentin than the CTC in most of the evaluated conditions. The bleaching agent was not effective in whitening the stained restored teeth.
\end{abstract}

Descriptors: Composites resin; tooth bleaching; tensile strength. 


\section{INTRODUCTION}

Currently, patients' demand for aesthetic procedures has increased in dental practices. Therefore, aiming at improving the esthetics, restorative materials, such as resin composites, have been widely used to simulate the natural color, translucency and texture of teeth ${ }^{1}$. However, resin composite restorations may change color in the buccal environment over time. The integrity and the color stability of restorations can be adversely affected by beverage consumption such as coffee, tea and wine. The staining agents can cause physical or chemical degradation to the structure of the resin composite restorations, compromising their quality ${ }^{1,2}$.

Bleaching procedures have been indicated to treat pigmented or darkened teeth as they are easy and cost-effective to treatments ${ }^{3}$. However, patients that undergo such treatments may have restored teeth and the bleaching gel can increase the solubility of the materials. Therefore, the adhesives and the composite resins degrade, changing the color of the composite materials and compromising the lifetime of the restorations ${ }^{4}$. Composite materials may change color after the application of hydrogen and carbamide peroxide ${ }^{5}$. The bleaching action on the properties of the resin material depend on some factors such as the volume of the organic matrix, the filler type and the composite conversion levels ${ }^{4}$.

Recently, a new group of resin composites was introduced in the market, the so-called 'bulk fill resin composites'. These materials feature new technology, comprising modified monomers (stress-relieving monomers) and incorporating different types of fillers (polymer particles and fiberglass rod segments) to minimize the shrinkage stress ${ }^{6}$. In addition, manufacturers have incorporated reactive alternative photoinitiators to the organic matrix, increasing the filler size and improving the curing depth of the bulk fill resin composites ${ }^{7}$. These resin composites were developed to allow bulk placement of increments up to 4 or $5 \mathrm{~mm}$, skipping the time-consuming layering process ${ }^{8}$. There is limited information concerning the discoloration behavior of bulk fill resin composites, as well as the effect of the bleaching action on them ${ }^{2,9,10}$.
Therefore, the purpose of this in vitro study was to evaluate the color change and the microtensile bond strength of bulk fill resin composites in dentin after the immersion in commonly consumed beverages and the application of bleaching systems. The null hypotheses tested in this study were the following: 1) There is no difference in the color change between the bulk fill and the incremental conventional resin composites after pigmentation and bleaching; 2) The color of the resin composites after immersion in several beverages is not affected by the application of bleaching systems; 3) There is no difference in the bond strength between the bulk fill and the incremental conventional resin composites after pigmentation followed by bleaching.

\section{METHOD}

Forty-five healthy human molar teeth were used in this research study, having the approval from the Research Ethics Committee of the University of Paraíba (protocol 55981116.2.0000.5188). Teeth were cleaned, stored in distilled water and used one month after extraction.

Tooth roots were embedded in self-curing acrylic resin and the occlusal enamel was removed using a water-cooling diamond saw (Extec, Enfield, CT, USA), aiming at simulating the cavity preparation. The exposed occlusal surface of the dentin was wet-abraded with silicon carbide paper (600 grit) (Carborundum Abrasivos, Recife, PE, Brasil), for 60 seconds, using a polishing device (Politriz ERIOS - 27000, São Paulo, SP, Brazil) to standardize the smear layer.

The teeth were randomly distributed in three groups according to the resin composites $(n=15)$ : Filtek Bulk Fill (3M ESPE, St. Paul, MN, USA), Tetric N Ceram Bulk Fill (Ivoclar-Vivadent, Bendererstrasse Schaan, Germany) and Z100 (3M ESPE, St. Paul, MN, USA). The composition and the batch number of each material are shown in Table 1.

For the restorative procedure, the adhesive system Adper Single Bond 2 (3M ESPE, St. Paul, MN, USA) was applied following the manufacturers' instructions. After finishing the bonding process, the teeth were restored according to the placement technique:

Table 1. Composition, brand and batch number of materials used

\begin{tabular}{|c|c|c|}
\hline Manufacturer/Batch number & Composite & Composition \\
\hline 3M ESPE-St. Paul, MN, EUA/588345 & $\mathrm{Z} 100$ & $\begin{array}{l}\text { Bis-GMA, TEGDMA, Zirconia/silica with } 66 \% \text { by weight in volume. Size } \\
\text { range: between } 0.01 \text { and } 3.5 \mu \mathrm{m} \text { (mean: } 0.6 \mu \mathrm{m}) \text {. }\end{array}$ \\
\hline $\begin{array}{l}\text { Ivoclar-Vivadent, Bendererstrasse, } \\
\text { Schaan, Germany/V35948 }\end{array}$ & $\begin{array}{l}\text { Tetric N Ceram } \\
\text { Bulk Fill }\end{array}$ & $\begin{array}{l}\text { Dimethacrylates ( } 19-21 \% \text { weight) and } 75-77 \% \text { by weight }(53-55 \% \text { by } \\
\text { volume) of inorganic fillers (mean: } 0.6 \mu \mathrm{m}) \text {. The fillers consist of barium } \\
\text { glass, prepolymer, ytterbium trifluoride and mixed oxide. Size range: } \\
\text { between } 0.04 \text { and } 3 \mu \mathrm{m} \text {. }\end{array}$ \\
\hline 3M ESPE-St. Paul, MN, EUA/N692414 & Filtek Bulk Fill & $\begin{array}{l}\text { AUDMA, UDMA, and 1, 12-dodecane-DMA. Combination of a } \\
\text { non-agglomerated } 20 \mathrm{~nm} \text { silica filler, a non-agglomerated } 4 \text { to } 11 \mathrm{~nm} \text { zirconia } \\
\text { filler, an aggregated zirconia/silica cluster filler ( } 20 \mathrm{~nm} \text { silica and } 4 \text { to } 11 \mathrm{~nm} \\
\text { zirconia), and a ytterbium trifluoride filler consisting of agglomerate } \\
\text { (100 nm). } 76.5 \% \text { by weight ( } 58.4 \% \text { by volume). }\end{array}$ \\
\hline
\end{tabular}

Bis-GMA = bisfenol A glicidil metacrilato; UDMA = urethane dimethacrylate; AUDMA = urethane dimethacrylate aromatic; TEGDMA = Triethylene glycol dimethacrylate. 
incremental (control) or bulk fill methods. Teeth from the control group were restored using three increments of resin composites (Z100-3M ESPE St. Paul, MN, USA) of $2 \mathrm{~mm}$ that were placed on the dentin surface. Each increment was light-cured for 40 seconds, using a LED light curing device set at $800 \mathrm{~mW} / \mathrm{cm}^{2}$ (Emitter C, SCHUSTER, Santa Maria, RS, Brazil). For the bulk-fill method, a 4-mm increment of Filtek Bulk Fill Posterior and Tetric N Ceram Bulk Fill was placed on the dentin surface, using a specific matrix. Then, the Filtek Bulk Fill Posterior increment was light cured, using a light curing device set at $800 \mathrm{~mW} / \mathrm{cm}^{2}$ (Emitter C, SCHUSTER, Santa Maria, RS, Brazil), for 40 seconds, while the increment of Tetric N Ceram Bulk Fill was light cured for 20 seconds, following the manufacturer's instructions. The restored teeth were storage in distilled water at $37^{\circ} \mathrm{C}\left( \pm 1^{\circ} \mathrm{C}\right)$ for 24 hours.

After the storage period, baseline color measurements were taken using a spectrophotometer (Vita Zahnfabrik, Bad Säckingen, Germany). Three measurements were taken for each restored tooth and the average reading calculated. The average of each specimen was calculated applying the Commission International de L'Eclairege $\mathrm{L} * \mathrm{a} * \mathrm{~b} *($ CIELAB) color space system. The CIELAB measures the chroma and the values in three coordinates: $\mathrm{L} *$, lightness measured from 0 (black) to 100 (white), a* color in the red $(a *<0)$ and the green $(a *>0)$ axis, and $b *$, color in the blue $(b *<0)$ and the yellow $(b *>0)$ axis. For the color measurement procedure, a probe tip was placed perpendicular to the center of each specimen and driven into the surface of the specimens for accurate measurement. The measurement procedures were repeated three times. All measurements were taken on a white background to eliminate light.

After the initial color analysis, the teeth restored with conventional and two bulk fill resin composites were distributed in three groups according to the beverage type: distilled water, coffee (Nescafe Classic, Nestlé, Vevey, Switzerland) and red wine (Oremus, Serra Gaúcha, Brazil) ( $\mathrm{n}=5)$. For the solution preparation, $6 \mathrm{~g}$ of coffee were added to $300 \mathrm{ml}$ of boiling water $\left(80 \pm 5^{\circ} \mathrm{C}\right)$. The specimens were immersed in one of the beverages for 72 hours and the immersion dispenser was changed every 24 hours. Then, the restored teeth were rinsed with distilled water for 20 seconds and submitted to a second color spectrophotometer analysis, as previously described. The magnitude of the total color difference was determined by applying the formula $\Delta \mathrm{E}=\left[(\Delta \mathrm{L})^{2}+(\Delta \mathrm{a})^{2}+(\Delta \mathrm{b})^{2}\right]^{1 / 2} \cdot \Delta \mathrm{L}^{*}, \Delta \mathrm{a}^{*}, \Delta \mathrm{b}^{*}$ are the differences in $L^{\star}, a^{*}$, and $b^{\star}$ values, before and after immersion at a time interval ( 72 hours).

For the bleaching procedure, the Whiteness HP Blue Calcium (FGM, Joinville, SC, Brazil), a 35\% hydrogen peroxide-based dental whitening system, was used for all the specimens, following the manufacturer's specifications. The gel was applied, once per session, for 40 minutes, by the same trained user and under the same condition. Every 10 minutes, the gel was activated by shaking the microbrush (FGM, Joinville, Brazil) to release any oxygen bubbles and renew the gel contact with the material. At the end of the application, the gel was removed from the samples, with an aspiration cannula, and washed with water for 20 seconds, then, restored in distilled water at $37^{\circ} \mathrm{C}$. The gel was applied twice, with a seven-day gap between the applications, and following the protocol mentioned above. Then, the quantitative color analysis was performed after the contact with the bleaching agent.

After the whitening process, the restored teeth were sectioned longitudinally in the mesiodistal and buccolingual directions across the bonded interface with a slow-speed diamond saw (Labcut 1010, Extec, Enfield, CT, USA). Then, the specimens were sectioned transversally in the cervical region to obtain $1 \mathrm{~mm}^{2} \times 8 \mathrm{~mm}$ bars. Ten bars from each tooth were used for micro-tensile bond strength ( $\mu \mathrm{TBS})$.

In order to apply the $\mu$ TBS testing, the bars were attached to a testing jig with a cyanoacrylate glue (Super Bond Gel - Locite Brasil Ltda) and subjected to a tensile load, at a crosshead speed of $15 \mathrm{~mm} / \mathrm{min}$, until failure (Odeme, Luzerna, SC, Brazil). The $\mu$ TBS values ( $\mathrm{MPa}$ ) were calculated by dividing the load in failure by the cross-sectional bonding area.

After applying the $\mu$ TBS testing, the fractured specimens were observed using an optical microscope (HMV-2, Shimadzu, Kyoto, Japan) with 200X magnification, and the fracture type classified as follows: Type I - cohesive fracture in the adhesive; Type II - cohesive fracture in the dentin; Type III - cohesive fracture in the hybrid layer; Type IV - mixed fracture: cohesive fracture in the adhesive and hybrid fracture in the layer; Type $\mathrm{V}$ - fracture in the composite.

Data from the quantitative color $(\Delta \mathrm{E})$ measurements were submitted to the Kruskal-Wallis and the Wilcoxon statistical tests. The ANOVA and the Bonferroni tests $(\mathrm{p}<0.05)$ were applied to analyze the data from the $\mu$ TBS testing. The fracture analysis was presented through descriptive statistics.

\section{RESULT}

Table 2 shows the mean values for the $\Delta \mathrm{E}$ in the experimental groups. In most of the studied conditions, no difference was seen for the $\Delta \mathrm{E}$ values between the bulk fill and the incremental conventional resin composites, after pigmentation or use of bleaching processes. Additionally, the $\Delta \mathrm{E}$ values were not significantly different, before and after bleaching, for all the resin composites.

Table 3 shows the mean and standard deviation values for the $\mu \mathrm{TBS}(\mathrm{MPa})$ in all the experimental groups. The bulk fill resin composite presented higher $\mu$ TBS values than the conventional resin composites after exposure to distilled water, wine, and whitening processes.

The percentage of specimens, according to the fracture type for the experimental groups, are shown in Table 4. The prevailing failure pattern observed was the mixed failure (cohesive failure in the adhesive and cohesive failure in the hybrid layer-type IV) in all the groups, except for the group exposed to coffee, in which the failure pattern was fracture in the composite (type V), for the Filtek Bulk Fill, and cohesive fracture in the adhesive (type I), for the Tetric N Ceramic Bulk Fill. 
Table 2. Mean and standard deviation of $\Delta \mathrm{E}$ values for different resin composites after exposure to different beverages and bleaching process

\begin{tabular}{|c|c|c|c|}
\hline \multicolumn{4}{|c|}{ COFFEE } \\
\hline COMPOSITE & AFTER IMMERSION & AFTER BLEACHING & $\mathbf{p}$ \\
\hline $\mathrm{Z} 100$ & $27.02(4.45)$ & $24.45(2.83)$ & 0.13 \\
\hline Filtek Bulk Fill & $19.45(1.43)$ & $18.45(0.83)$ & 0.13 \\
\hline Tetric $N$ ceram Bulk Fill & $18.97(11.92)$ & $19.89(12.50)$ & 0.80 \\
\hline $\mathbf{p}$ & 0.059 & 0.050 & \\
\hline \multicolumn{4}{|c|}{ DISTILLED WATER } \\
\hline COMPOSITE & AFTER IMMERSION & AFTER BLEACHING & $\mathbf{p}$ \\
\hline $\mathrm{Z} 100$ & $1.07(0.76)$ & $1.23(0.40)$ & 0.50 \\
\hline Filtek Bulk Fill & $1.81(0.41)$ & $1.13(0.36)$ & 0.43 \\
\hline Tetric N ceram Bulk Fill & $0.86(0.38)$ & $1.27(0.38)$ & 0.13 \\
\hline $\mathbf{p}$ & $0.034^{\star}$ & 0.93 & \\
\hline \multicolumn{4}{|c|}{ WINE } \\
\hline COMPOSITE & AFTER IMMERSION & AFTER BLEACHING & $\mathbf{P}$ \\
\hline $\mathrm{Z} 100$ & $28.28(9.41)$ & $29.82(9.13)$ & 0.43 \\
\hline Filtek Bulk Fill & $20.64(6.43)$ & $22.91(6.95)$ & 0.89 \\
\hline Tetric N ceram Bulk Fill & $21.7(6.95)$ & $22.66(6.88)$ & 0.13 \\
\hline $\mathbf{p}$ & 0.27 & 0.39 & \\
\hline
\end{tabular}

${ }^{*}$ Statistical significance $(\mathrm{p}<0.05)$.

Table 3. Mean and standard deviations of $\mu \mathrm{TBS}(\mathrm{MPa})$ of different resin composites after exposure to different beverages and bleaching process

\begin{tabular}{|c|c|}
\hline \multicolumn{2}{|c|}{ COFFEE } \\
\hline COMPOSITE & \\
\hline $\mathrm{Z100}$ & $59.00(17.71) \mathrm{A}$ \\
\hline Filtek Bulk Fill & $60.30(20.40) \mathrm{A}$ \\
\hline Tetric N ceram Bulk Fill & $54.48(13.51) \mathrm{A}$ \\
\hline $\mathrm{p}$ & 0.21 \\
\hline \multicolumn{2}{|c|}{ DISTILLED WATER } \\
\hline \multicolumn{2}{|l|}{ COMPOSITE } \\
\hline Z100 & $35.46(11.24) \mathrm{A}$ \\
\hline Filtek Bulk Fill & $49.25(14.28) \mathrm{B}$ \\
\hline Tetric N ceram Bulk Fill & $42.93(16.53) \mathrm{B}$ \\
\hline $\mathrm{p}$ & $0.00^{*}$ \\
\hline \multicolumn{2}{|c|}{ WINE } \\
\hline \multicolumn{2}{|l|}{ COMPOSITE } \\
\hline $\mathrm{Z} 100$ & $36.36(11.56) \mathrm{A}$ \\
\hline Filtek Bulk Fill & $46.11(13.42) \mathrm{B}$ \\
\hline Tetric N ceram Bulk Fill & 45.97 (17.21)B \\
\hline $\mathrm{p}$ & $0.001^{*}$ \\
\hline
\end{tabular}

Means followed by the different uppercase letter on the same column show statistical differences between resin composites within the same immersion solution. ${ }^{*}$ Statistical significance $(\mathrm{p}<0.05)$. 
Table 4. Percentage (\%) of specimens according to the fracture mode of different resin composites after exposure to different beverages and bleaching process

\begin{tabular}{|c|c|c|c|c|c|}
\hline \multicolumn{6}{|c|}{ COFFEE } \\
\hline & & & patt & & \\
\hline \multirow{2}{*}{$\mathrm{Z} 100$} & I & II & III & IV & $\mathrm{V}$ \\
\hline & 8 & 0 & 0 & 86 & 6 \\
\hline \multirow{2}{*}{ Filtek Bulk Fill } & I & II & III & IV & $\mathrm{V}$ \\
\hline & 14 & 0 & 0 & 36 & 50 \\
\hline \multirow{2}{*}{ Tetric N ceram Bulk Fill } & I & II & III & IV & $\mathrm{V}$ \\
\hline & 56 & 0 & 0 & 34 & 10 \\
\hline \multicolumn{6}{|c|}{ DISTILLED WATER } \\
\hline
\end{tabular}

\begin{tabular}{|c|c|c|c|c|c|}
\hline & & & patt & & \\
\hline \multirow{2}{*}{$\mathrm{Z100}$} & I & II & III & IV & $\mathrm{V}$ \\
\hline & 12 & 0 & 0 & 78 & 10 \\
\hline \multirow{2}{*}{ Filtek Bulk Fill } & I & II & III & IV & $\mathrm{V}$ \\
\hline & 2 & 0 & 0 & 66 & 32 \\
\hline \multirow{2}{*}{ Tetric N ceram Bulk Fill } & I & II & III & IV & $\mathrm{V}$ \\
\hline & 14 & 0 & 0 & 60 & 26 \\
\hline \multicolumn{6}{|c|}{ WINE } \\
\hline
\end{tabular}

Fracture patterns (\%)

\begin{tabular}{|c|c|c|c|c|c|}
\hline \multirow{2}{*}{ Z100 } & I & II & III & IV & V \\
\hline & 4 & 0 & 0 & 72 & 14 \\
\hline \multirow{2}{*}{ Filtek Bulk Fill } & I & II & III & IV & $\mathrm{V}$ \\
\hline & 4 & 0 & 0 & 70 & 26 \\
\hline \multirow{2}{*}{ Tetric N ceram Bulk Fill } & I & II & III & IV & V \\
\hline & 14 & 0 & 0 & 76 & 10 \\
\hline
\end{tabular}

Type I = cohesive fracture in the adhesive; Type II = cohesive fracture in dentin; Type III = cohesive fracture in the hybrid layer; Type IV = mixed fracture (cohesive in adhesive and hybrid layer); Type $\mathrm{V}=$ composite fracture.

\section{DISCUSSION}

According to the findings reported in this research study, the bulk fill resin composites presented similar behavior than the incremental conventional resin composite when exposed to regular beverages (wine and coffee). The beverages caused discoloration in all the resin composites and the bleaching agent did not reduce the staining of the resin composites, previously exposed to extrinsic pigments. Furthermore, the bulk fill resin composites presented better bond strength to the dentin than the incremental resin composite in most of the studied groups.

Aiming at observing the color stability of direct restorative materials, this research study evaluated the $\Delta \mathrm{E}$ from two bulk-fill resin composites and one conventional resin composite after the immersion in red wine and coffee. The $\Delta \mathrm{E}$ value showed the color difference of dental materials and tooth surfaces before and after an intervention, in which the $\Delta \mathrm{E}$ value 3.3 is considered clinically acceptable ${ }^{10,11}$. Based on our results, the immersion solutions caused severe staining on all the resin composites, being the $\Delta \mathrm{E}$ values greater than 3.3 in all the experimental groups exposed to red wine and coffee. The adsorption and absorption of pigments, which occurs in the organic phase of resin-based materials, is what causes the resin composite discoloration. Red wine presents a high concentration of pigment molecules, low $\mathrm{pH}$ and alcohol, causing the softening of the polymeric matrix ${ }^{12,13}$. As for coffee, it contains significant number of staining agents such as gallic acid, favoring the staining process ${ }^{10,14}$. On the other hand, when the specimens were immersed in distilled water, the $\Delta \mathrm{E}$ values were lower than 3.3, being clinically acceptable.

The color change of materials can be influenced by intrinsic factors such as the physiochemical characteristics of the resin structure as polymerization initiators, accelerators, stability of the resin-filler interface and water sorption of the polymerized resin 
matrix ${ }^{15,16}$. Although bulk fill resin composites feature changes in the filler content and/or the organic matrix, their $\Delta \mathrm{E}$ values were not significantly different from the incremental conventional resin composites values, after the immersion in beverages and the application of bleaching processes. Therefore, the first hypotheses were rejected. This result may be explained by the discoloration resistance of the resin composite being more dependent on the monomer content and surface roughness, than the size of the filler particles ${ }^{17}$. As known, the studied bulk fill resin composites present similar resin matrix (Bis-GMA, Bis-EMA, UDMA), therefore, the discoloration was no attributed to the additives admixed to modify the polymerization process ${ }^{16}$.

Another important factor to be considered in achieving satisfactory color stability of materials is the composite conversion level. This parameter plays an important role in the development of the intrinsic or extrinsic staining of the resin composites, influencing the hydrophilicity, water sorption and adsorption and dissolution potential of materials ${ }^{10}$. In this present research study, light intensity of $800 \mathrm{~mW} / \mathrm{cm}^{2} \mathrm{f}$ was applied, for 40 or 20 seconds, to provide proper curing depth to materials and, consequently, maximum color stability. Both types of composites stained under the same condition, despite of the use of bulk fill resin composites in a single increment of $4 \mathrm{~mm}$ thickness. These results are in accordance with previous studies ${ }^{2,16}$, in which the bulk fill resin composites showed a similar color susceptibility when compared to conventional resin composites.

The reaction between the bleaching agent and the pigmented substance is based on a complex oxidation that results in the opening of pigmented carbon rings, converting the rings into clearer intermediate chains ${ }^{18}$. In this in vitro study, the $\Delta \mathrm{E}$ values did not show significant differences, before and after the bleaching process, for all the tested resin composites. Hence, the second null hypothesis was rejected. It seems that the bleaching agent did not cause a significant effect on the color change of the resin composites. All the evaluated materials showed $\Delta \mathrm{E}$ values clinically unacceptable $(\Delta \mathrm{E}>3.3)^{10,11}$, even after undergoing bleaching processes. The effect of the bleaching agent on the resin composites depends on the difference between the composition of the organic matrix and the filler particles ${ }^{19}$. The resin composite used in this study has the same resin in its composition (Bis-GMA, Bis-EMA, UDMA), but differ regarding the filler content. Nevertheless, fillers are basically glass or ceramic, thus, the influence of hydrogen peroxide on them can be very small ${ }^{4}$.

Considering the bond strength, the bulk fill composites presented higher $\mu$ TBS values than the incremental conventional resin composite after tooth staining and application of bleaching processes, except for the coffee group. These results are in accordance with additional studies $^{20,21}$. Bleaching agents may negatively influence the bond strength of resin composites in the dentin ${ }^{22-24}$. During bleaching, reactive oxygen radicals are released, changing the physical properties of the tooth-restoration interface ${ }^{24}$. These free radicals can damage the hybrid layer that is responsible for the adhesion mechanism of the composite to the dental structure ${ }^{25}$. After the bleaching process, the most common fracture pattern observed was the mixed failure (IV). Previous reports have shown that the prevailing fracture pattern observed was the cohesive failure in the dentin, which was followed by the mixed failure ${ }^{19,25}$. An in vitro study evaluated the bond strength of conventional composites, after dentin bleaching, and found that the predominant type of fracture was the mixed fracture ${ }^{22}$.

The results achieved in this research study indicate that staining solutions and bleaching processes influence the properties of both the bulk fill resin composites and the incremental conventional resin composite. However, this in vitro study does not reproduce intraoral conditions. Therefore, further investigations, using different materials and conditions to simulate the buccal environment, are necessary to validate these findings.

\section{CONCLUSION}

The studied bulk fill resin composites seem to present a similar performance than the conventional resins for color change, after immersion in beverages and application of bleaching processes. On the other hand, the resin composites presented a superior bond strength to the dentin under most of the evaluated experimental conditions.

\section{REFERENCES}

1. Nasim I, Neelakantan P, Sujeer R, Subbarao CV. Color stability of microfilled, microhybrid and nanocomposite resins: an in vitro study. J Dent. 2010;38(Suppl 2):e137-42. http://dx.doi.org/10.1016/j.jdent.2010.05.020. PMid:20553993.

2. El Gezawi L, Kaisarly D, Al-Saleh H, ArRejaie A, Al-Harbi F, Kunzelmann KH. Degradation potential of bulk versus incrementally applied and indirect composites: color, microhardness, and surface deterioration. Oper Dent. 2016 Nov-Dec;41(6):e195-208. http://dx.doi.org/10.2341/15195-L. PMid:27820694.

3. Klaric Sever E, Simenc N, Rakic M, Skenderovic H, Sever I, Tarle Z. Effects of bleaching agent on physical and aesthetic properties of restoratives materials. Dent Mater J. 2016;35(5):788-95. http://dx.doi.org/10.4012/dmj.2015-443. PMid:27725516.

4. Silva Costa SX, Becker AB, Souza Rastelli AN, Monteiro Loffredo LC, Andrade MF, Bagnato VS. Effect of four bleaching regimes on color changes and microhardness of dental nanofilled composite. Int J Dent. 2009;2009:313845. http://dx.doi.org/10.1155/2009/313845. PMid:20339576.

5. Canay S, Cehreli MC. The effect of current bleaching agents on the color of light- polymerized composites in vitro. J Prosthet Dent. 2003 May;89(5):474-8. http://dx.doi.org/10.1016/S0022-3913(03)00168-9. PMid:12806325.

6. Fronza BM, Rueggeberg FA, Braga RR, Mogilevych B, Soares LE, Martin AA, et al. Monomer conversion, microhardness, internal marginal adaptation, and shrinkage stress of bulk fill resin composites. Dent Mater. 2015 Dec;31(12):1542-51. http://dx.doi.org/10.1016/j. dental.2015.10.001. PMid:26608118. 
7. Bucuta S, Ilie N. Light transmittance and micro-mechanical properties of bulk fill vs. conventional resin based composites. Clin Oral Investig. 2014 Nov;18(8):1991-2000. http://dx.doi.org/10.1007/s00784-013-1177-y. PMid:24414570.

8. Ilie N, Bucuta S, Draenert M. Bulk-fill resin-based composites: an in vitro assessment of their mechanical performance. Oper Dent. 2013 Nov-Dec;38(6):618-25. http://dx.doi.org/10.2341/12-395-L. PMid:23570302.

9. Lago M, Mozzaquatro LR, Rodrigues C, Kaizer MR, Mallmann A, Jacques LB. Influence of bleaching agents on color and translucency of aged resin composites. J Esthet Restor Dent. 2017 Sep;29(5):368-77. http://dx.doi.org/10.1111/jerd.12261. PMid:27599875.

10. Shamszadeh S, Sheikh-Al-Eslamian SM, Hasani E, Abrandabadi AN, Panahandeh N. Color stability of the bulk-fill composite resins with different thickness in response to coffee/water immersion. Int J Dent. 2016;2016:7186140. http://dx.doi.org/10.1155/2016/7186140. PMid:27403163.

11. Yap AU, Sim CP, Loh WL, Teo JH. Human-eye versus computerized color matching. Oper Dent. 1999 Nov-Dec;24(6):358-63. PMid:10823085.

12. Catelan A, Briso AL, Sundfeld RH, Goiato MC, dos Santos PH. Color stability of sealed composite resin restorative materials after ultraviolet artificial aging and immersion in staining solutions. J Prosthet Dent. 2011 Apr;105(4):236-41. http://dx.doi.org/10.1016/S0022-3913(11)600383. PMid:21458648.

13. Van Groeningen G, Jongebloed W, Arends J. Composite degradation in vivo. Dent Mater. 1986 Oct;2(5):225-7. http://dx.doi.org/10.1016/ S0109-5641(86)80018-5. PMid:3468026.

14. Dietschi D, Campanile G, Holz J, Meyer JM. Comparison of the color stability of ten new-generation composites: an in vitro study. Dent Mater. 1994 Nov;10(6):353-62. http://dx.doi.org/10.1016/0109-5641(94)90059-0. PMid:7498599.

15. Koc-Vural U, Baltacioglu I, Altinci P. Color stability of bulk-fill and incremental-fill resin-based composites polished with aluminum-oxide impregnated disks. Restor Dent Endod. 2017 May;42(2):118-24. http://dx.doi.org/10.5395/rde.2017.42.2.118. PMid:28503477.

16. Gönülol N, Yilmaz F. The effects of finishing and polishing techniques on surface roughness and color stability of nanocomposites. J Dent. 2012 Dec;40(Suppl 2):e64-70. http://dx.doi.org/10.1016/j.jdent.2012.07.005. PMid:22819955.

17. Lynch E, Sheerin A, Samarawickrama DY, Atherton MA, Claxson AW, Hawkes J, et al. Molecular mechanisms of the bleaching actions associated with commercially-available whitening oral health care products. J Ir Dent Assoc. 1995;41(4):94-102. PMid:8975074.

18. Hannig C, Duong S, Becker K, Brunner E, Kahler E, Attin T. Effect of bleaching on subsurface micro-hardness of composite and a polyacid modified composite. Dent Mater. 2007 Feb;23(2):198-203. http://dx.doi.org/10.1016/j.dental.2006.01.008. PMid:16546248.

19. Flury S, Peutzfeldt A, Lussi A. Influence of increment thickness on microhardness and dentin bond strength of bulk fill resin composites. Dent Mater. 2014 Oct;30(10):1104-12. http://dx.doi.org/10.1016/j.dental.2014.07.001. PMid:25086481.

20. Kumagai RY, Zeidan LC, Rodrigues JA, Reis AF, Roulet JF. Bond strenght of a flowable bulk fill resin composite in class II MOD cavities. J Adhes Dent. 2015 Aug;17(5):427-32. http://dx.doi.org/10.3290/j.jad.a35012. PMid:26525007.

21. Barcellos DC, Benetti P, Fernandes VV Jr, Valera MC. Effect of carbamide peroxide bleaching gel concentration on the bond strength of dental substrates and resin composite. Oper Dent. 2010 Jul-Aug;35(4):463-9. http://dx.doi.org/10.2341/09-242-L. PMid:20672732.

22. Didier VF, Batista AUD, Montenegro RV, Fonseca RB, Carvalho FG, Barros S, et al. Influence of hydrogen peroxide-based bleaching agents on the bond strength of resin-enamel/dentin interfaces. Int J Adhes Adhes. 2013 Dec;47:141-5. http://dx.doi.org/10.1016/j.ijadhadh.2013.08.009.

23. Alqahtani MQ. Tooth-bleaching procedures and their controversial effects: a literature review. Saudi Dent J. 2014 Apr;26(2):33-46. http:// dx.doi.org/10.1016/j.sdentj.2014.02.002. PMid:25408594.

24. Oliveira MT, Andrade MAC, Michels M. Oxygen release, microleakage and shear bond strength of composite restorations after home dental bleaching. Rev Odonto Ciênc. 2011;26(1):45-9. http://dx.doi.org/10.1590/S1980-65232011000100011.

25. Omran TA, Garoushi S, Abdulmajeed AA, Lassila LV, Vallittu PK. Influence of increment thickness on dentin bond strength and light transmission of composite base materials. Clin Oral Investig. 2017 Jun;21(5):1717-24. http://dx.doi.org/10.1007/s00784-016-1953-6. PMid:27613613.

\section{CONFLICTS OF INTERESTS}

The authors declare no conflicts of interest.

\section{${ }^{\star}$ CORRESPONDING AUTHOR}

Renally Bezerra Wanderley Lima, UNICAMP - Universidade Estadual de Campinas, Faculdade de Odontologia, Av. Limeira, 901, 13414-903 Piracicaba - SP, Brasil, e-mail: renallywanderley@gmail.com 